\title{
Theory and Practice of Vulnerability to Disasters in Flood Prone Areas in Chikwawa, Malawi
}

\author{
J. Mtembenuzeni, J. Kushe* \\ Department of Geography and Earth Sciences, Mzuzu University, Private Bag 201, Luwinga Mzuzu 2, Malawi
}

Copyright $\mathrm{O} 2018$ by authors, all rights reserved. Authors agree that this article remains permanently open access under the terms of the Creative Commons Attribution License 4.0 International License

\begin{abstract}
Contrary to the nature of occurrence of floods in Malawi, for communities, floods have a social face and should be understood as a social disaster other than natural disasters. A study was carried out in Chikuse Traditional Authority area in Chikhwawa, Malawi, to understand why people are affected by floods despite the long history of their occurrence. Assessment of the vulnerabilities of people in the area was critically reviewed in relation to pressure and release model (PAR) and also the access model. Data was collected from the communities through interviews and focus group discussions and also the use of key informant's interviews. Cluster and circle approach was used to understand the interrelationships pressure conditions, access/release conditions, vulnerability and disaster situation. This approach help to find the relationship that exist between people normal life condition with inherent vulnerabilities and the way they react to, cope with and recover from hazardous situation and whether their condition will enable

waiting for relief from government and epistemic organizations. There was no or poor demarcation between normal life and disaster situation for the vulnerable groups and that was among the major obstacles to full recovery from a disaster situation. The research found a mismatch between what has been documented as the root causes of vulnerability in the study area and the actual situation. The research also founds out that apart from social, political and economic causes of vulnerability in flood areas, there were other factors that also make people vulnerable such as; attitude of people, cultural beliefs, poor social network, and not just the drainage density of the area. Uncoordinated and unplanned efforts in terms of mitigation strategies for reducing people's vulnerability compounded the disaster situation. The study concluded that during floods people will be pushed to a disaster situation because of their capacities the floods and their effects. The research suggested the need to build capacity for the people in this area which will help build resilience or ease relocation.
\end{abstract} them avoid disasters or predispose them to disasters. An appraisal of the route to recovery or next disaster was made to explain the social causation of likelihood of recurrence of disasters in the study area. In this case an analysis common treats of the groups which ended into disaster situation were considered the causal factors of the disaster. The probability of the next disaster was considered as product of the social causation in presence of floods as pressure conditions. It was found out that the disaster in the study area varied between individual and families because of their vulnerability condition. Lack of access to land, wealth, natural and social resources and linkages was found to be the major cause of pressure condition. Those with low score of access to resources were more vulnerable and were likely to be driven into the disaster condition in presence of a flooding event. Ill health, poor nutrition, long duration of recovery was typical notable characteristics of the more vulnerable individuals than those with access to release condition. Families which had access to shelter, food, wealth natural resources and land recovered quickly from the hazard and some completely avoided the disaster unlike those who did have resources who ended up in
Keywords Theory, Practice, Vulnerability, Disaster, Flood

\section{Introduction}

Theoretically researchers have written much on flood risk but have neglected practical aspects of people's vulnerability on the ground. Despite warnings people insist living in places prone to floods due to the benefit obtained during and after floods [1]. When human and economic losses are determined for planning of relief services, those who experience disasters are conceptualized as a homogenous group called 'victims', a category which overlooks differences in terms of gender, caste, class, age or physical and mental ability [1] and also the state their normal life in disaster free times. However, 'disasters' unfold in varying geographic, political, socioeconomic and cultural contexts [2] and people's ability to respond, cope with or adapt reflects unevenly distributed patterns of 
vulnerability structured by access to and control over resources, the extent of diversified livelihood strategies, physical location (community settlement patterns , population density ) or personal endowments (skills, education, key survival and recovery resources) and access to information and communication systems [3]. This is so because some people think that by the mere fact one being found in flood prone areas, they are vulnerable to flooding which is contrary to the people who actually stay in these areas. In addition what other people may believe in are the problems with floods are not actually the real problems faced on the ground. In Malawi, the most frequently reported natural hazards are floods and they account for over 40 per cent of all disasters [4]. The major flood areas in Malawi are along the shores Lake Malawi, the main rivers, and in low lying areas. Virtually the whole of Malawi is at risk to floods but the Lower Shire Valley is the most affected area. The threats of the flood hazard have become complex and interrelated whilst the number of the vulnerable is growing fast. Reports indicate that the southern Lower Shire region of Malawi, which stretches down to the border with Mozambique, has suffered most due to its low, marshy terrain and the presence of several rivers flowing into the already swollen Shire River [4]. High intensity and long duration rains across plateau and high rising areas overseeing the Shire to the west in Shire Highlands and east across the western border have caused the rivers in the area to burst their banks, displacing thousands of people, flooding homes and farmland, and causing severe damage to property and crops. Although the loss of life has been minimal because of the government warnings but thousands are at risk because of the timing of the floods. February is considered a lean month when most food stocks are used up ahead of the March/April harvest [5]. With much of the harvest washed away, food becomes a priority. The lack of food and shelter increases the vulnerability of flood victims, heavily impacting on their health and nutritional status. The already serious situation has been compounded by damaged sanitation facilities and contaminated water, increasing the threat of cholera and malaria. The area under study is one of the most dominant affected areas in Chikwawa where floods occur yearly and most of lives and properties are lost and between 2000 up to 2012 this area has been annually experiencing floods [6].

\subsection{Problem Statement}

Flood is probably the most devastating, widespread and frequent natural hazard of the world. Since Malawi was awakened by floods that occurred in Phalombe in 1991 [7], there have been reports about how the vulnerable people are affected in one way or the other. However have presented the situations theoretically unlike what really has been the case on the ground (practicality). A gap exist in relation to what is thought of as vulnerability and the actual vulnerabilities people have in flood prone areas of Chikuse in Chikhwawa.

\subsection{Significance of the Study}

In absence of the correct understanding of vulnerability to floods in Chikuse area in Chikhwawa people will keep on suffering from floods without adequate and proper ways address to the risk. The International Strategy for Disaster Reduction [8], define vulnerability "a set of conditions and processes resulting from physical, social, environmental and economic factors, which increase the susceptibility of a community to the impact of hazards."

\subsection{Limitation of Study}

The study period was limited as it was meant for undergraduate students to be submitted in partial fulfilment of the undergraduate degree.

\subsection{Objectives}

\subsubsection{General Objective}

The general aim of the study is to assess the theoretical and practical understanding of vulnerabilities in flood prone areas of Chikuse, Traditional Authority Makhwira in Chikhwawa District.

\subsubsection{Specific Objectives}

The specific objectives of this study include the following:

1. To find out the nature and cause of the vulnerability in people.

2. To investigate the level of vulnerability based on social economy condition of the people in the study area.

3. To examine the extent of coping mechanisms on flood hazards or disasters.

4. To find out reasons why the vulnerable people still remain in the flood prone areas.

5. To find out what could be the most effective mitigation strategies based on the condition in study area.

\section{Materials and Methods}

\subsection{Description of the Study Area}

The study was conducted in Group Village Headman Chikuse Area of Traditional Authority Makhwira in Chikwawa District. It comprises of four villages namely; Wilson, Gusu, Chikuse 1 and 2. Chikuse is the main area that is hit by floods almost yearly. This area is located along the Shire River and gets flooded due to several rivers pouring their water in this Shire River. Among these rivers is Mwanza River. The area has an altitude of $100 \mathrm{~m}$ above the sea level or below. The land is almost flat with several river tributaries. The area has good and fertile soils that attract people for cultivation of crops without applying inorganic fertilizer. 


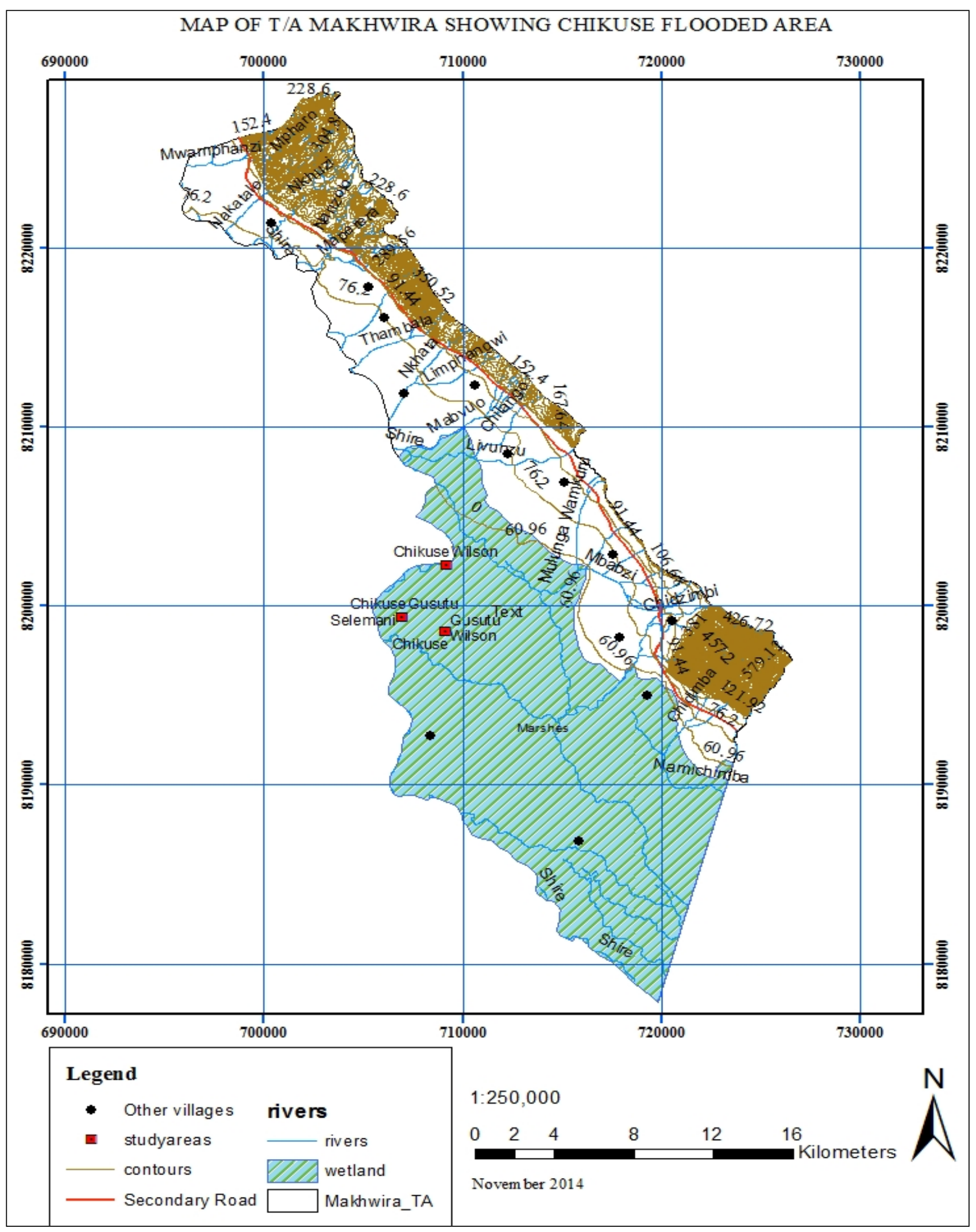

Figure 1. Map showing Chikuse Flood Prone Area of T/A Makhwira in Chikwawa District 


\subsection{Study Design}

For this study, a field trip to Chikwawa District was a good opportunity to make direct observations. It provided chances to hear useful comments that could never be found in books - and yet so relevant and helpful to the research. Adequate information on various aspects of floods such as the extent of vulnerability, some measures of mitigation, and problems regarding lack of funds and lack of proper and on-time coordination were gathered.

A questionnaire was administered to the subjects in Chikwawa District. It was answered by 30 adults whose ages ranged between 16 to 60 years who were likely to be the ones who were once the victims mainly from the area under study. Key informants were interviewed comprised the Desk Officer for Disaster Management in Chikwawa District, a senior officer from Chikwawa Police, and the chief of Traditional Authority (TA) Makhwira. In order to ensure the validity and reliability of the collected data, this study employed both qualitative and quantitative research methods. Qualitative method was used for the purpose of finding out diversity of opinions and understanding the effectiveness of various aspects of the flood vulnerability and management. For a balanced view, the research tools comprise four tools. An observation was made, a semi-structured interview was conducted, and a questionnaire was undertaken. The final method that was employed for the investigation of the relationships and processes of interest was the review of documentation. Computation were made of the data collected to establish frequencies and trends to determine magnitudes of the challenges.

\subsection{Sampling Techniques}

Purposive sampling was used to get information from only those residents in the area who had experienced a flood.

\subsection{Sample Collection and Analysis}

Data analyzing involved rearranging the responses. Descriptive analysis which was in form of qualitative description was carried out on the responses of the subjects regarding their vulnerability that was in terms of social, economic and physical. The data collected was also analyzed manually and the use of computer through Microsoft word and Microsoft excel.

\section{Results and Discussion}

The sample of the study consisted of three (3) villages and each was represented by ten (10) respondents. These villages were; Gusu, Wilson and Chikuse. All of the respondents answered the questionnaires and observations were made by the researcher.

\subsection{The Nature and Causes of the Vulnerability of People in Chikuse Area}

While floods can play an invigorating role in this case study area's ecology by bringing fish and other species into the wetlands and depositing nutrients in the soil, floods of greater intensity or duration than expected severely affected this community [9]. The respondents indicated that the nature and cause of vulnerability in Chikuse Area are due to the following factors. All the respondents indicated that really in this area of study people are more vulnerable to floods. The following were indicated as the most nature and the causes of people vulnerability: Almost seventeen percent $(17 \%)$ of them said that being confined at one place and caught by crocodiles, thirty three percent (33\%) said walking long distance to get maize mill during the flooding, thirty three percent (33\%) said that receiving of little support at an evacuation centre, and another seventeen percent $(17 \%)$ no support given to the foreigners.

"I must have been here for about 10 years now and I saw the first flood that entered into our house. I stayed at home with my mother for almost two weeks -we lived on the grains we had stored at home, to us it was a normal life because we had nowhere to escape, to us whether it means that flooded water has exceeded the level of my breast it does not bother us provided we should have food for us to survive. ......we know for sure that without floods we cannot stay in this area," a certain villager describes, referring to her Wilson village. 


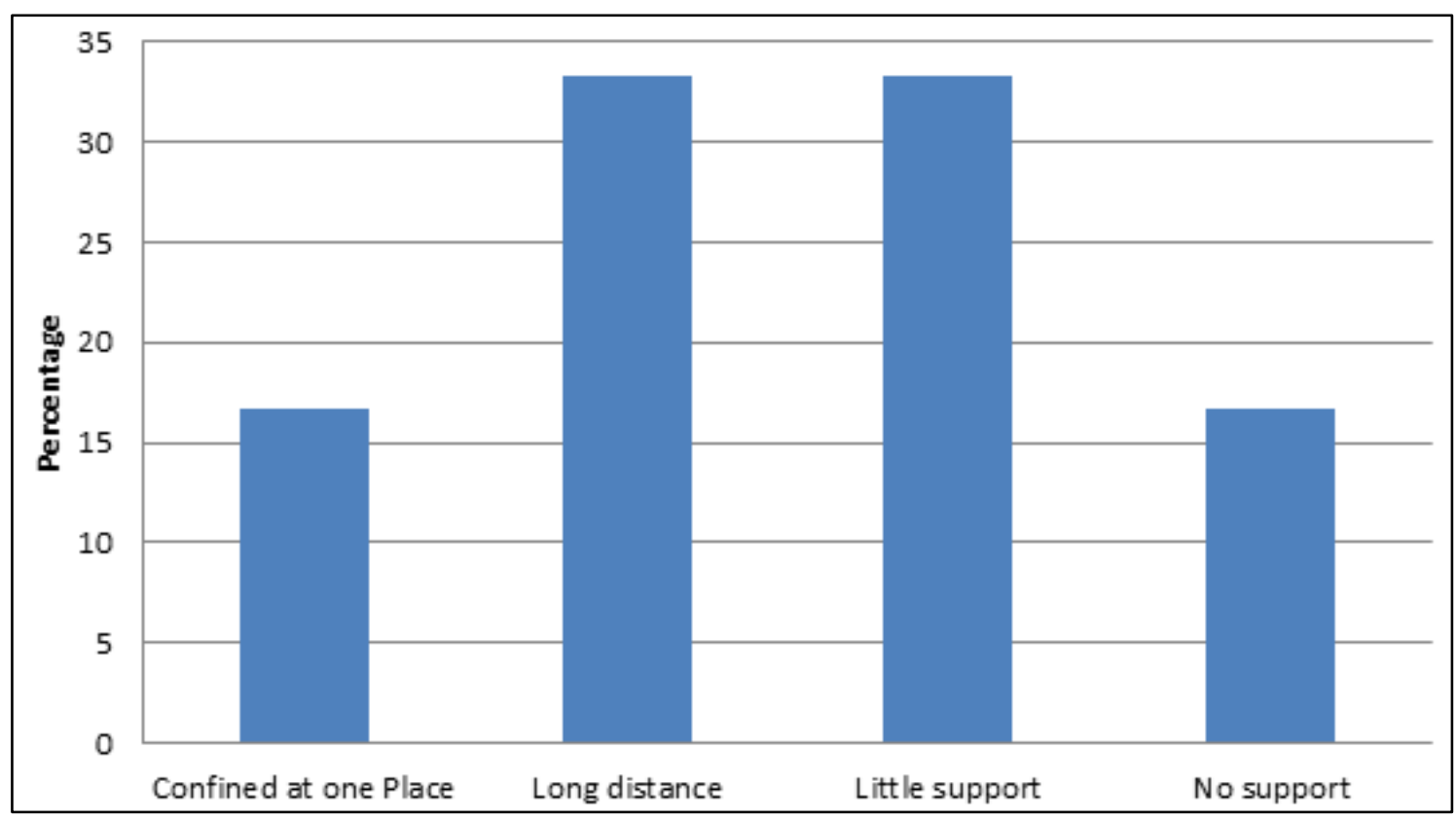

Figure 2. Showing the Nature and Causes of Vulnerability of People in Chikuse Area

\subsection{The Level of Vulnerability Based on Social Economic Condition of the People in the Study Area}

All the respondents admitted that the level of their vulnerability is based on the social economy. According to the observation made the vulnerability is due the following: it was discovered that the area has the housing units which are poor and have insufficient basic water and sanitation, roads and poor markets. Of one hundred percent $(100 \%)$ respondents only ten percent $(10 \%)$ had pin latrines (toilets).

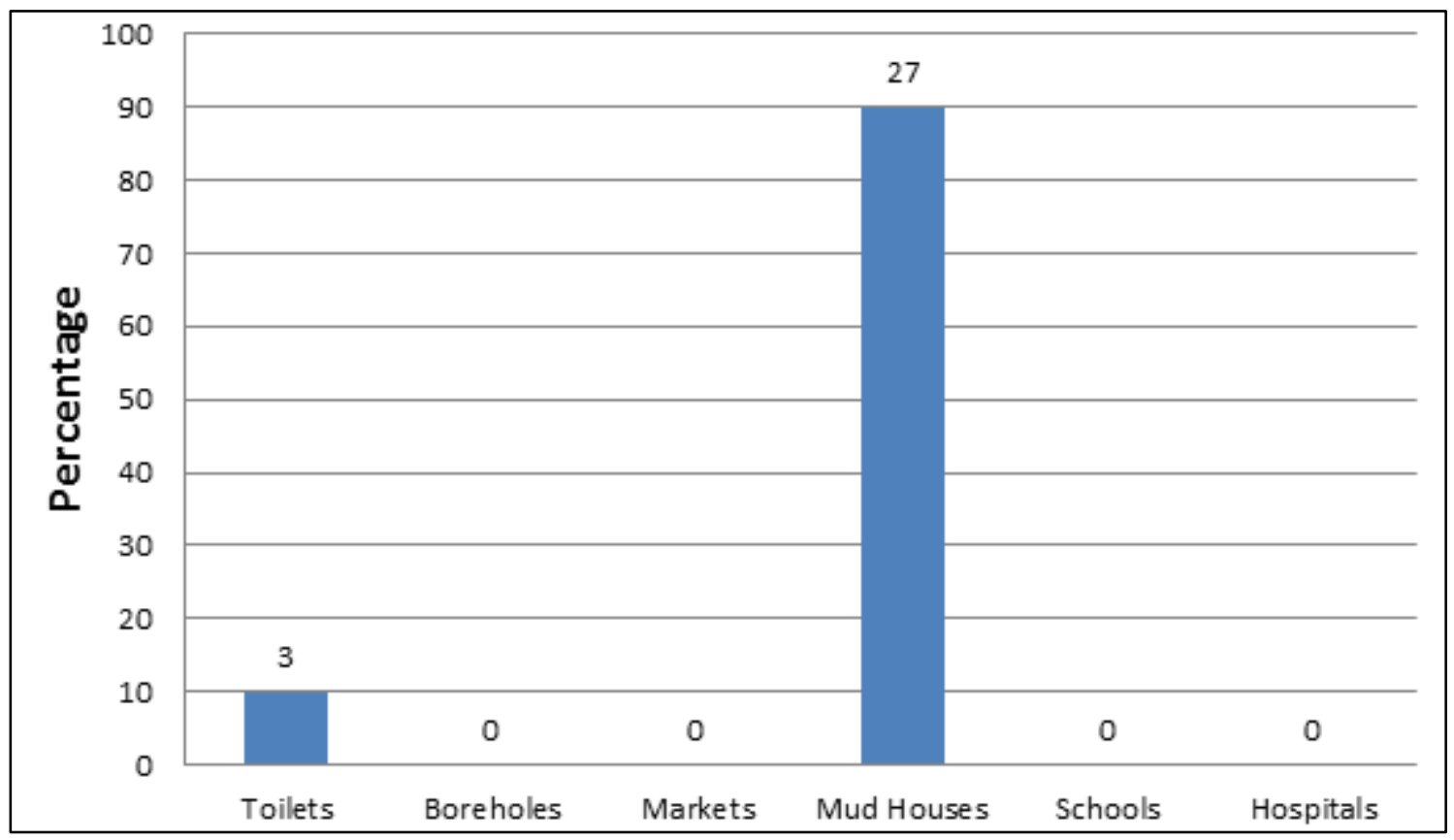

Figure 3. Showing the Level of Vulnerability based on Social Economic condition of the people in the study area

"There were also sentiments expressed buy the people in the area: ....... are no boreholes in this area all people access water through unprotected wells, which was dangerous because the area is located in low flat areas." High water tables presents abundance of groundwater source, leading to increase of the use of unprotected shallow wells as sources of water. As indicated above, only a few people have pit latrines but the rest use the nearby bushes. There were no any under-five clinics even a government primary school in Chikuse area which has a 
sizable population of youth which result in more people failing to access medical attention when they get sick and high illiteracy levels respectively. Since most of the residents are illiterate, they cannot obtain formal employment with most deriving their income from farming. Rising from lack of employment and high illiteracy levels, most residents earn very low incomes from small scale businesses, barter trading, and wages from piece works "ganyu". Barter trading is mainly done due to the fact that the area has no community market where people can sell their farm inputs after a harvest. Due to unemployment and lack of sustainable means of livelihoods, poor farming methods are always practiced just for the people to earn their living.

Theoretically, this research involves The Pressure and Release Model (Crunch) which shows that a disaster happens only if a hazard meets a vulnerable situation. It shows how the cause of vulnerability can be traced back from the unsafe condition, through economic and social (dynamic) pressures to underlying root cause. Pressure model is an organized framework outlining a hierarchy of causal factors that together constitute the pre-conditions for a disaster. It can be described as a pathway, progression of vulnerability or a chain of causation. It is a sequence of factors and processes that leads one from a disaster event and its proximate causes back over more distant factors and processes that initially may seem to have little to do with causing the disaster [10].

Pressures are caused and increased by a set of underlying causes which encourages those in position of power to behave in a certain way. These underlying causes may be political ideas, economic principles or due to cultural issues or practices. People's vulnerability at local and international levels can often be linked back to poor governance, inequality, greed, injustice and prejudice [10]. These issues may seem far from the affected community but they can have a powerful influence. For example, political decision about land reform can result in people losing land or work, making them more vulnerable to hazard. But this is not the case with floods in this study area because people's vulnerability is linked with poverty

\subsection{The Extent of Coping Mechanisms on Floods Hazards or Disasters}

The study focus on how the community's response to protect and cope with the identified element exposed to risk - income, physical structures, disruption of path way, Injuries and life losses, and their personal belongings. Result shows that more than half of the households perceived the flood as a nuisance to them rather than a catastrophe. They opt to stay in the area for the proximity to the source of economic livelihood. The people apply more than three (3) coping mechanisms in order to live in the area. For these people, coping mechanism are an integral part of their life to live with the effects of flood. They said that they construct homes at an ant hill, building homes at a safer and higher elevation and construction of local havens called "Tchete."

Three factors were identified that influence the coping mechanisms employed by the community at different flood stages -before, during and after. Income, access to assistance, and geographical location show significant relationships with the community's coping mechanisms. However, other respondents when asked how do they cope up during or after the flood, they said that they do not have any coping mechanism because during this time almost all their properties that they depend on are destroyed by flood. Majority of them said that no any central government, followed or foreign aid Agencies. Ten percent $(10 \%)$ out of one hundred percent $(100 \%)$ were able to sell their livestock like goats and the maize, to cope with flood hazards within the community. They also said that poor flood-affected families take shelter in higher ant hills where they (victims) construct a small "Tchete" house like a nest where they can stay as long as the area remains flooded (weeks or months). 


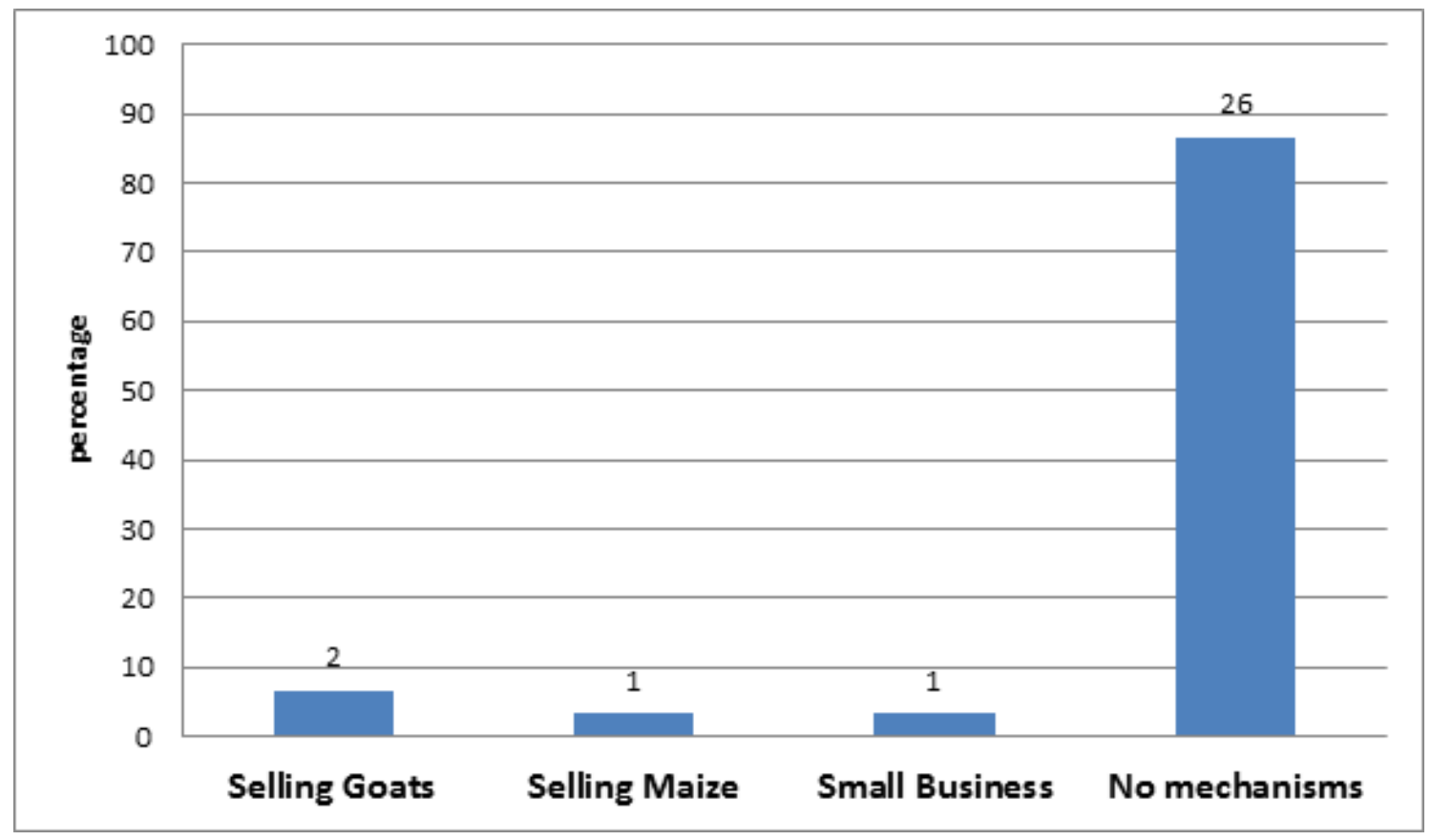

Figure 4. Showing the extent of coping mechanisms on flood hazards or disasters

Families who lose their home and livelihood and remain without any thing to eat and other sources of income move to flood relief camps in the district (Kalulu Area) which is about Fifteen (15) kilometres from this case study area.

Most of the flood-affected people barely have any savings or food stocks. Therefore, it can be concluded that just a few people, the selling off assets particularly livestock, is one of the most common coping strategies.

Also the existence of formal credit institutions to help rehabilitate flood-struck households in the study area is rare. Flood-affected families mainly cope with a flood crisis with the help of informal credit. Relatives, neighbours, and family friends help flood-affected families by providing loans and other assistance, or flood-affected families buy food from local shops on a credit basis. Sometimes, richer, well-off families in a village lend money to flood-affected local residents.

There are no leading NGOs that deal with micro- credit in the study area. Although existing literature suggests that these NGOs play an important role in ex post coping response to flood disasters by distributing flood relief, agricultural inputs and subsidized micro credits in flood-affected regions [11]. In contrast most key informants in this particular area stated that they play almost no role at all. Most flood-affected families depend on relatives, neighbours, and informal microcredit systems to cope with floods. According to this research it has revealed that almost victims of the affected farmers in Chikuse area mitigated their income and asset losses by selling land, livestock, and other belongings. This was observed in this case study though not mentioned by the key informants as an effective common coping strategy, possibly because of the fact that many floodplain residents in this specific case study area are so poor because more than half of the sample lives under the poverty threshold that they have no assets to sell.

The Access Model picks up the state of normal life and explains how people earn a livelihood with differential access to material, social and political resources [10]. In this case, if this Access model is critically analysed, it can be noted that it is contradicting with the situation being faced in this study area. Where if the area is under flood there is no role of any agency to help, no interacting with other actors like police. This might be case due to the geographical position of the area. For example, the area is surrounded by Shire River and other small tributaries which cause the situation to become tough for these agencies to help properly eventually the victims' vulnerability increases.

\subsection{The Reasons Why the Vulnerable People Still Remain in the Flood Prone Areas Despite Being Warned}

There were varied responses as to why people prefer to remain in this flooded area despite having knowledge that floods cause them to be vulnerable. This question though viewed to be simple but it was very crucial because Seventy percent $(70 \%)$ of the respondents said contrary to what thirty percent $(30 \%)$ other respondents said. The seventy percent of respondents said that, they are used in this area as a result they take this area as their only home.

They also said that they prefer to remain in this area during the floods for the fear of outbreak of diseases like, cholera and dysentery at an evacuation centre because if 
they are at this evacuation they noted that they are provided with only one toilet to be used by hundreds of people there. The people at the evacuation consist of men, women and youth. Then to them it is unethical and uncalled for. They also said that they always think that by going to an evacuation centre, it can be a wastage of time to come back to start cultivating rice as the level of water gets lowered. All of the respondents in this category were mostly those who came from distant (foreigners). For example, others came from Mozambique, and other districts of Malawi to settle in this area due to its fertility.

Table 1. Showing the reasons why the people still remain in the flood prone area.

\begin{tabular}{|c|c|c|}
\hline Reasons & Frequency & Percentage (\%) \\
\hline Used & 21 & 70 \\
\hline Ancestral & 9 & 30 \\
\hline Fishing & 9 & 30 \\
\hline $\begin{array}{c}\text { Fear of Disease } \\
\text { outbreak }\end{array}$ & 30 & 100 \\
\hline Time Wastage & 30 & 100 \\
\hline
\end{tabular}

The remaining thirty percent $(30 \%)$ of the respondents said that they cannot go out of this area because it was given to them by their forefathers and this area belongs to them. "I cannot go out of this area because I am a Group Village Headman and I have my subordinates. If we go out of this area will I maintain my chieftaincy there?" asked a certain village leader. The issue of wasting of time as they go to a certain evacuation centre was also highlighted with this group meaning to say that they opt to stay in the area to catch up with time for cultivating rice so that they can have enough food for the next growing season. This group also noted that at the evacuation centre, they are given little support from the government and other concerned organisations to aid their various needs. "We only get two (2) blankets, one (1) fifty kilogram $(50 \mathrm{~kg})$ of dry maize, five kilograms $(5 \mathrm{~kg}$ ) of beans, five (5) plastic cups, four (4) plates and one (1) bucket, and we are eight (8) in my family, how can we share two (2) blankets." A certain man lamented. This group also raised an issue of fishing that during floods they catch a lot of fish which supplement them to on as source of food. Therefore, culture is also playing a leading role to the vulnerability of the victims. For example, societal status is the one which is making these people to be more vulnerable. As noted, most people (victims) in this area are the ones who are responsible for land distribution for other people to settle and cultivate. Now, it becomes hard for these people to lose that responsibility (status) hence be vulnerable in this flooded area.

As observed, it was noted that most of the respondents were foreigners while only thirty percent $(30 \%)$ of the respondents were the landowners. In this case, it can be argued that foreigners are more vulnerable because they are coming from long distant places that it can be very difficult for them to go back and that the landowners do not show interest of going out of this area to get at least a higher area. While the landowners, they fear of losing their home and chieftaincy because wherever they are going, they are uncertain whether they can maintain their positions or that they will be recognised as village headmen or leaders in foreign land. On the same point, it has been noted with great concern that though the government always insist to push the people out of their disastrous area but up to now, it has failed to identify a safer place for it citizens to resettle and be protected. So just saying that these people should go out of such areas but no land identified for them to stay on, it also increases their vulnerability that is why the people insist to live in this area because so far no place has been identified.

Furthermore, if there these people have decided to go out of such places, what will government do with this area? Will other people not occupy this area? If the government can tell these people clearly what it can do with such area if people go out of that area, it can possible to convince them. So in this case, it can be argued that failure of government to come up with proper strategic plan to convince these people also increase their vulnerability.

\subsection{Cost Benefit Analysis (CBA)}

There are also many views from other peoples' perspectives all over Malawi as to why these people opt to stay in this area. One of the views that other people give is the issue of dependency. They say that people in flooded affected areas stay there for them to get an aid from either government of other organisations. But as the respondents were asked to do Cost Benefit Analysis (CBA) as to which they benefit much between what they normally realise through floods and those items they get through aid from the government as well as organisations. All respondents $(100 \%)$ strongly said that what they get in the flooded area is more than what government give them mainly at the evacuation centre. So this also increases their vulnerability.

\subsection{Mitigation Strategies Based on the Condition in this Study Area}

This research also looked for information concerning what other stakeholders are doing to help the victims in other flooded areas. According to the Desk Officer for Disaster Management in Chikwawa District and Evangelical Association of Malawi's Project Officer in the same district they said that they have built two (2) Save Havens one at T/A Ngowe and one at Khungubwe respectively. These Save Havens are disaster adaptive infrastructures that can be occupied by the victims. Having close look at these Havens, they have been built in dry areas unlike the actually areas that normal experiences floods, which becomes also a threat because it can take more hours for the victims to travel a long distance to reach 
these two places hence increase in their vulnerability. Though it is good idea to build the havens but it could be very appropriate if these havens were constructed in the same flooded areas so that people should not take too long to get this place so that their vulnerability of walking long distance could be reduced and this can be called as impractical.

\subsection{Discussion}

The study found that there are differences in how floods occur and their effects and what they believe is the problem with them. Two models have been defined and discussed in the literature review and theoretical framework, in chapter 2. In this chapter the researcher has used them in the formulation of a conceptual framework that, which is recommended for understanding vulnerability in Chikuse. Pressure and Release model shows the elements of the conceptual framework. These have been categorized into those related to vulnerability namely; defining root causes, identification of dynamic pressures and creation of safe conditions. While Access model shows some of the things which make the victims to be able to earn a living before, during and after the floods. The data collected and analysed in this paper imply a number of things. In the first place it indicates that people in Chikuse area are vulnerable due to floods that are always experienced in this area. The findings in this chapter emphasised the problems caused by floods in Chikuse area. According to Wisner et al [10] they argue that the most important root causes that give rise to vulnerability (and which reproduce vulnerability over time) are economic, demographic and political processes. Issues like; altitude, proximity to Shire River and river network these entire have also significance to the cause and nature of the vulnerability problem in this study area.

The indicators show that people are vulnerable partly not because they are poor though there is relationship between vulnerability and poverty. Being confined at one place, caught by crocodiles, walking long distance to get maize mill during the flooding, receiving of little support at an evacuation centre, and no support given to the foreigners who came from Mozambique other areas like Thyolo, Mzimba, etc. are some of the factors that cause the people in this area to be vulnerable unlike what the Pressure and Release model is presenting as causes of vulnerability during hazards or disasters.

Out of the one hundred per cent $(100 \%)$ interviewed with semi-structured questionnaires, none expert, the researcher was told that all decided to live in Chikuse because they want to cultivate so that they can eliminate their poverty because they cannot afford to buy food. The general opinion is well reflected in the following quotation which was said by a 54 year old man," what can I do? Where can I go? I only hope that one day; my life can change through farming in this area. I also hope the government will seriously consider that even us the poor, need better life. But for now, even if it rained heavily, I would not go anywhere, unless someone comes to my aid."

It is obvious that the victims though affected by floods they are supposed to have coping mechanisms for them to keep on living. Nine per cent $(10 \%)$ out of one hundred per cent $(100 \%)$ were able to sell their livestock like goats and the maize, to cope with flood hazards within the community. They also said that poor flood-affected families take shelter in higher ant hills where they (victims) construct a small "Tchete" house like a nest where they can stay as long as the area remains flooded for some time. This is contrary to what other people have been speculating about the floods any disaster's victims that most of them depend on the aid from either government or any charity organisation. Victims always find ways for them to sustain a living in this area.

As noted that most people prefer to stay in this area because they have no readily identified place for them to live on as opposed to what has been decided by the government that these people need to be reallocated. Theoretically, it is true that the people here are vulnerable because they insist to live in this area but practically no place has been identified by the government to help these people from being vulnerable. Others, mainly landowners as indicated that they fear of losing their chieftaincy ship because they are uncertain if they go out of this area that where they are going they will not be leaders. In this case the government too should make some efforts to arrange proper ways to avoid conflicts where these people can be resettled. As also noted in the responses about why these people prefer to stay in this area it can be concluded that culture also plays a big role for people to be vulnerable to flood disasters. In this way, Wisner et al, (2003) did not include the cultural aspect to be one of the root causes of vulnerability in flood areas. On the same, though not given in the responses but still can be included as root cause is the issue of religious beliefs since some cultures go hand in hand with some religious beliefs. This element too was overlooked by Wisner et al in their Pressure and Release model.

Even building of two (2) Save Havens one at T/A Ngowe and one at Khungubwe by government and Evangelical Association of Malawi (EAM) respectively is not practical solution to help flood victims. Practically, these Save Havens could have been built in the same area to ease their vulnerability by walking short distance to get where these Havens are. But by just building these Havens in dry area both government and EAM have not solved the problem because this has also increase their vulnerability. If they were willing to help these people they would have involved the victims to decide where these Havens should be built. In this case the project lacked the element of consultation for victims to participate in any decision made outside their involvement. In this case, it can also be concluded that people are also vulnerable in this area because of uncoordinated planning in terms of mitigation 
strategies that both government and other humanitarian agencies provide. Therefore, there is no relationship between theory and practice of vulnerability in all flood prone areas. Some of these theories can work better in other areas but not Chikuse area.

\section{Conclusion and Recommendation}

\subsection{Conclusions}

Having looked at the theory and practice of vulnerabilities in flood prone areas in Malawi, mainly in Chikuse area of Traditional Authority Makhwira in Chikwawa District, people are vulnerabilities in flood prone in the study area due to difference in culture, altitude, river networks as well as uncoordinated planning during mitigation implementation.

Compliance to calls for evacuation would reducing vulnerability in this area, however it requires commitment from all stakeholders. There is need for an effective capacity building program for the people of Chikuse area. People need education and warnings about flood hazards and disasters. The people should be trained and empowered with disaster management skills so that they can contribute to finding solutions to mitigate floods in this area.

\subsection{Recommendations}

This study looked at the relationship between theory and practice of vulnerabilities in flood prone areas. From the assessment, which was done, it should come out clear to government and all stakeholders that mitigation strategies that are top-bottom in nature do increase people's vulnerability. Therefore, the following recommendations should be taken into consideration.

1. It should be remembered that at all the time the most victims in flood prone areas are children, youth as well as elderly people and most cause is the cultural beliefs. Therefore, authorities who are involved in planning strategies should first of all civic educate the people in such areas.

2. All children who have school going age should also access education in this area so that as they become educated they may become the opposing forces of bad cultural beliefs which make people to be vulnerable, which can yield positive results and eventually reduce people's vulnerability which can come due to behaviour change.

\subsection{Opportunities for Further Study}

1. Similar study should be carried out at a larger scale

2. Indigenous knowledge on the management of floods in flood prone areas

3. Pattern of flooding events in time and space in Lower Shire Valley

\section{REFERENCES}

[1] Scheneiderbauer, S.; and Enhrlich, D: Risk, Hazard and People's Vulnerability to Natural Hazards. (2004); A Review of Definitions, Concepts and Data. European Commission Joint Research Centre. EUR 21410 EN.

[2] Watts, M. J.; Bohle, H.G. (1993): The space of vulnerability: the causal structure of hunger and famine. (1993) In: Progress in Human Geography. Vol. 17, pp. 43-67

[3] IPCC (International Programme on Climate Change); Climate Change 2001: Synthesis Report (2002). Geneva, International Programme on Climate Change Secretariat, World Meteorological Organization.

[4] Mijoni, P.L.; "Management of floods in Malawi: case study of the Lower Shire River Valley", (2006); MSc thesis in Global Security, Cranfield University.

[5] Adger, W. N.; Vulnerability. (2006); In: Global Environmental change, vol. 16, pp. 268-281

[6] Chikwawa District Development Plan 2006-2009

[7] Alfred Ntonga, Daily Times, 1991

[8] ISDR; UN/ISDR Living with Risk, a Global Review of Disaster Reduction Initiatives. (2004): Geneva, United Nations.

[9] Alexander, D. The study of natural disasters, 1977-1997: Some reflections on a changing field of knowledge. (1997): In: Disasters. Vol.21, pp.283-304

[10] Wisner B, Blaikie P, Cannon T, Davis I At Risk: Natural Hazards, People's Vulnerability, and Disasters. (2004); 2nd edition. London: Routledge.

[11] United Nations (UN); Report of the world conference on disaster reduction. (2005); A/CONF. 206/6, Kobe, Hyogo. 